\title{
Education Outreach: Raising Awareness of Diabetes and Pharmacy Careers
}

\author{
Christopher L. Flanigan, Catherine Santanello \\ Southern Illinois University Edwardsville (SIUE) School of Pharmacy, Edwardsville, IL, USA \\ Email: cflanig@siue.edu, csantan@siue.edu \\ Received 6 August 2014; revised 3 September 2014; accepted 17 September 2014 \\ Copyright (C) 2014 by authors and Scientific Research Publishing Inc. \\ This work is licensed under the Creative Commons Attribution International License (CC BY). \\ http://creativecommons.org/licenses/by/4.0/

(c) (i) Open Access

\begin{abstract}
Objectives: 1) To demonstrate that education outreach in public schools by students in pharmacy education programs is effective at increasing knowledge of important health topics; 2) To assess subject attitude towards pharmacy careers after education outreach. Study: A lecture was constructed providing participants with information about careers in pharmacy, diabetes, and information about health literacy. A multiple choice paper-based quiz covering the presented content both preceded and followed each delivery of the lecture. Increases in post-lecture scores of content-knowledge questions were seen in 10 of 11 questions, which indicated an overall increased knowledge from baseline. An additional question, which gauged student interest in pharmacy careers, showed a $10 \%$ increase in those who indicated they considered pharmacy as a career. Conclusions: The lectures, delivered by a student pharmacist, were effective in increasing awareness and knowledge of pharmacy as a career, diabetes as an important health issue, and health literacy as a problem pharmacists and other healthcare providers encounter on a daily basis.
\end{abstract}

\section{Keywords}

Pharmacy, Education Outreach, Diabetes Education, Health Literacy

\section{Introduction}

The Millennium Poll was a survey related to health, poverty, and economic growth. It was administered worldwide with the intention of using the results to prepare the Millennium Report of the Secretary-General of the United Nations. The findings of the survey confirmed that optimal health was consistently ranked above all other things desired in the lives of people [1] [2]. In order to maintain their own health and the health of loved-ones, people rely on whatever health information is available to them. This may include information obtained from friends and colleagues, healthcare workers, the media, Internet sources, etc. Knowing the best sources for accu- 
rate information is essential for maintaining good health. Obtaining, understanding, and processing that health information in order to make health decisions that are appropriate are the core principles of a concept referred to as health literacy [3].

A goal of the National Action Plan to Improve Health Literacy is for children to graduate with health literacy skills developed from early childhood through higher education [4].

Health literacy education disseminated throughout the spectrum of a person's education can help to cement a solid foundation of health-related knowledge as an adult [5]. The 2003 National Assessment of Adult Literacy (NAAL) recommends that "Policymakers, health care administrators, educators, and health care and public health professionals can take advantage of the many options at their disposal to create a society that is sensitive to the health literacy needs of its population and provides accessible health information that matches the health literacy skills of the American public" [4].

Pharmacists are consistently perceived by US citizens as one of the most trusted professions [6]. In fact, pharmacists ranked second to nurses as individuals with the highest honesty and ethical standards as related to their professions [6]. Pharmacists are in a unique position as a trusted and accessible healthcare provider to make significant differences in the lives of the people in the communities they serve. One such way to make a difference and satisfy the NAAL recommendation is through educational outreach to local communities [7].

This study was conducted to demonstrate that community education outreach by a student pharmacist can increase awareness of issues surrounding health literacy and improve knowledge of health issues. It can also serve a vital purpose of promoting interest in pharmacy careers and potentially attracting the most qualified applicants to local schools of pharmacy.

\section{Design and Methods}

One southern Illinois and two Saint Louis Metro-East high schools were contacted to gauge interest for participation in the study. All three schools elected to participate. Approval of the study was obtained by the Southern Illinois University Edwardsville (SIUE) Institutional Review Board in September of 2013. Signed and completed child assent and parental consent forms were sent home with students by each school to obtain parental approval and signature. Signed forms were obtained from each study participant prior to each study session.

Each participant received a twelve-question pre- and post-lecture quiz consisting entirely of multiple-choice questions (Appendix 1). The pre- and post-lecture quizzes were identical and measured knowledge of information retained as a result of the presentation. Each quiz was marked with a participant-chosen three-digit and three-letter combination. No two students chose the same three-letter combination. The alphanumeric combination was only used to match pre- and post-lecture quiz scores.

Once the participants completed the pre-lecture quiz, there was a 35-minute educational presentation conducted by the first author of this paper. The presentation was interspersed with multiple choice questions to make the activity more interactive. It included information about the important roles and responsibilities of pharmacists (slides 1 to 9), the level of education of pharmacists and information about career opportunities in pharmacy (slides 10 to 20). Additionally, health literacy was addressed in the presentation by defining the term, demonstrating basic skills, and educating students on such information as the average reading level of a US adult (slides 21 to 26).The presentation also covered information about diabetes mellitus, including the definition, pathophysiology, risks, signs and symptoms, and long-term complications of the disease (slides 27 to 36 ). The authors would be pleased to provide the PowerPoint presentation to any interested parties.

After the presentation, the participants completed the post-lecture quiz. The data from the pre-lecture quiz was compared to the data from the post-lecture quiz for each participant in the study to determine the difference in knowledge about pharmacy as a career, health literacy, and diabetes mellitus as a health issue.

\section{Results}

A total of 477 high school students completed the pre- and post-lecture quizzes and were active participants in the presentation discussion. An exact response rate could not be determined because the distribution of consent and assent forms was handled solely by each school. There were no students whose parents declined participation. Any students not participating simply did not return their signed consent and assent forms, which appears to be very common for all activities at school that require them. While exact demographic information could not be collected, all of the participants were in $10^{\text {th }}, 11^{\text {th }}$, or $12^{\text {th }}$ grade. 
Data from questions in Table 1 suggests anoverall increase in knowledge from baseline. However, results from some of the questions show only a marginal increase in knowledge, which could possibly be attributed to some baseline knowledge regarding diabetes.

Table 2 shows data from questions related to health literacy. Included in the table is one question that resulted in a decreased number of people who answered correctly compared to the pre-lecture question. Upon review of the question (Health literacy is simply the ability of a person to read.), it was determined that the question could have been written in a more absolute manner using the word "only the ability". Therefore, we feel that the students may have misinterpreted it. The other health literacy-related question, however, showed an increase in knowledge gained compared to baseline.

Data from Table 3 indicate an increase in knowledge from the pre-lecture quiz in the areas of pharmacy careers and pharmacy education information and requirements. The high pre-lecture scores for two of the questions suggest that students may have had some knowledge of tasks appropriated to pharmacists as well as activities pharmacists perform such as compounding. Regardless of this, the pre- and post-lecture scores for those questions increased by $6.3 \%$ and $22.9 \%$, respectively.

One particular question, not included in the tables above, was utilized to help gauge the interest of students towards pharmacy as a career. The question was true/false in nature and simply stated, "I have considered pharmacy as a career choice". Results from the pre-lecture quiz showed that 143 (29.9\%) responded true. Results from the post-lecture quiz indicated that 188 (39.3\%) responded true. There was a 9.4\% increase from the pre-lecture quiz in those who expressed an interest in pharmacy as a career. It might be that the gain in knowledge of pharmacy opportunity and education resulted in an increase in those who reported to be interested in

Table 1. Diabetes-related question data $(n=477)$.

\begin{tabular}{ccc}
\hline Objective & Pre-lecture & Post-lecture \\
\hline Define polyphagia & Number correct (\% correct) & Number correct (\% correct) \\
\cline { 2 - 3 } Distinguish blood and tissue glucose levels & $230(48.2)$ & $399(83.3)$ \\
Identify the role of insulin in the body & $128(26.8)$ & $135(28.2)$ \\
Define hyperglycemia & $265(55.6)$ & $301(62.8)$ \\
Recognize the prevalence of diabetes in the US & $326(82.3)$ \\
Identify common long-term complications of uncontrolled \\
hyperglycemia
\end{tabular}

Table 2. Health literacy-related question data $(\mathrm{n}=477)$.

\begin{tabular}{ccc}
\hline Objective & Pre-lecture & Post-lecture \\
\cline { 2 - 3 } Define health literacy & Number correct (\% correct) & Number correct (\% correct) \\
\hline Recognize the average reading level of adults in the US & $387(81.1)$ & $278(58.0)$ \\
\hline
\end{tabular}

Table 3. Career and education-related question data $(n=477)$.

\begin{tabular}{ccc}
\hline Objective & Pre-Lecture & Post-lecture \\
\cline { 2 - 3 } Define compounding & Number correct (\% correct) & Number correct (\% correct) \\
\hline $\begin{array}{l}\text { Identify years of pre-professional and professional } \\
\text { coursework requirement for the SIUE pharmacy program } \\
\text { Recognize appropriate tasks for community pharmacists }\end{array}$ & $303(63.5)$ & 314 (86.4) \\
\hline
\end{tabular}


pharmacy careers.

\section{Discussion}

Reaching out to the community to educate students on opportunities in pharmacy may attract more qualified and driven candidates into the profession of pharmacy. Strong pools of applicants can ultimately enhance schools of pharmacy, which can have long-term effects on the patients of those graduates and on the profession itself.

Community education outreach by pharmacists may be utilized to educate on important health topics to address at least one aspect of the health literacy crisis. Increasing knowledge of health topics such as diabetes empowers people to make better-informed decisions about their health as well as influence the health-related decisions of others in a positive manner.

Based on the data collected, it might be reasonable to conclude that outreach could be an effective effort to improve health literacy. People with adequate health literacy incur fewer healthcare costs, have better outcomes and a decreased number of hospitalizations, thus pharmacists should see this as a worthwhile endeavor [8]-[10].

Limitations to this study include a relatively small sample size and a relative lack of diversity in the sampled student population. If more students were sampled, especially from schools with students of a more diverse socio-economic background, areas where these types of public outreach programs could have a more optimal impact could be targeted.

\section{Conclusions}

This study indicates that education outreach is an important tool for addressing health literacy issues related to pharmacy. The baseline knowledge of the participating high school students regarding pharmacy careers, health literacy, and diabetes was enhanced as a result of this activity.

Pharmacy students, pharmacy faculty and practicing pharmacists are in a unique position to execute community education outreach objectives by providing free health education to children and the general population. Pharmacist-led education outreach can provide a valuable and economically favorable contribution to the health and welfare of people in the communities they serve. We suggest that more schools of pharmacy and other health sciences adopt similar programs because it is a great community outreach experience for students preparing for their careers in the health sciences.

\section{Disclosures}

A special thanks goes to the Meridian Society of SIUE for an award that provided financial assistance for this research.

\section{Financial Disclosure Statement}

This study was supported by a SIUE Meridian Society Award.

\section{Conflict of Interest Disclosure Statement}

The authors have no conflict of interest to disclose.

\section{References}

[1] Alleyne, G. and Cohen, D. (2002) Health, Economic Growth, and Poverty Reduction. World Health Organization, Geneva. http://whqlibdoc.who.int/publications/9241590092.pdf

[2] Sachs, J., et al. (2005) Investing in Development: A Practical Plan to Achieve the Millennium Development Goals. Earthscan, United Nations Development Programme.

[3] Health Literacy: Accurate, Accessible and Actionable Health Information for All. Centers for Disease Control and Prevention, 2013. http://www.cdc.gov/healthliteracy/

[4] Goal 3: Incorporate Accurate, Standards-Based, and Developmentally Appropriate Health and Science Information and Curricula in Child Care and Education Through the University Level. United States Centers for Disease Control and Prevention, 2011. http://www.cdc.gov/healthliteracy/planact/goals/goal3.html

[5] America’s Health Literacy: Why We Need Accessible Health Information. US Department of Health \& Human Ser- 
vices, 2008. http://www.health.gov/communication/literacy/issuebrief/

[6] Honest/Ethics in Professions. Gallup, Inc., 2012. http://www.gallup.com/poll/1654/honesty-ethics-professions.aspx

[7] DeRemer, C., Van Landingham, J., Carswell, J. and Killough, D. (2008) Pharmacy Outreach Education Program in Local Community. The American Journal of Pharmaceutical Education, 72, 94. http://dx.doi.org/10.5688/aj720494

[8] Andrus, M.R. and Roth, M.T. (2002) Health Literacy: A review. Pharmacotherapy, 22, 282-302. http://dx.doi.org/10.1592/phco.22.5.282.33191

[9] Nichols-English, G. and Poirier, S. (2000) Optimizing Adherence to Pharmaceutical Care Plans. Journal of American Pharmacists Association, 40, 475-485.

[10] Baker, D.W., Parker, R.M., Williams, M.V. and Clark, S. (1998) Health Literacy and the Risk of Hospital Admission. Journal of General Internal Medicine, 13, 791-798. http://dx.doi.org/10.1046/j.1525-1497.1998.00242.x 


\section{Appendix 1-Pre- and Post-Lecture Quiz}

1) The word "polyphagia" means:
a) increased hunger or appetite
b) increased thirst
c) increased need to urinate
d) increased need to defecate

2) Which of the following statements best describes a person with type 1 diabetes?
a) not enough blood glucose (sugar) in the blood and too much in the tissues of the body
b) not enough blood glucose (sugar) in the tissues and not enough in the blood
c) not enough blood glucose (sugar) in the tissues and too much in the blood
d) too much blood glucose (sugar) in the blood and too much in the tissues

3) Many people use insulin to treat their diabetes. How does insulin act in the body?
a) Insulin prevents the body from absorbing glucose and other carbohydrates from the food that the person might eat.
b) Insulin causes a variety of cells in the body to absorb glucose (sugar) from the blood.
c) Insulin prevents cells in the body from absorbing glucose (sugar) from the blood.
d) Insulin causes an increase in mood and energy, which then leads to a decrease in appetite.

4) Some pharmacists make drugs, a process or activity called:
a) formatting
b) contemplating
c) compounding
d) factoring

5) The word "hyperglycemia” means:
a) low blood glucose (sugar)
b) normal blood insulin level
c) low blood insulin level
d) high blood glucose (sugar)

6) Health literacy is the ability of an individual to read.
True
False

7) Students in pharmacy school at SIUE School of Pharmacy have which of the following requirements?

a) 2 years of pre-professional coursework; 5 years of professional coursework

b) 4 years of pre-professional coursework; 2 years of professional coursework

c) 3 years of pre-professional coursework; 4 years of professional coursework

d) 2 years of pre-professional coursework; 4 years of professional coursework

8) Community pharmacists are responsible for all of the following tasks EXCEPT:
a) dispensing medications
b) diagnosing patients with diseases
c) managing staff
d) talking to patients

9) Roughly 9.8 million children and adults in the United States are affected by diabetes.

True False

10) Uncontrolled blood glucose (sugar) can result in which of the following conditions EXCEPT:
a) blindness
b) kidney failure
c) nerve damage
d) weight loss

11) I have considered pharmacy as a career choice.
True
False

12) The average reading level of adults in the US is
a) $1^{\text {st }}$ Grade
b) $6^{\text {th }}$ Grade
c) $10^{\text {th }}$ Grade
d) $12^{\text {th }}$ Grade 
Scientific Research Publishing (SCIRP) is one of the largest Open Access journal publishers. It is currently publishing more than 200 open access, online, peer-reviewed journals covering a wide range of academic disciplines. SCIRP serves the worldwide academic communities and contributes to the progress and application of science with its publication.

Other selected journals from SCIRP are listed as below. Submit your manuscript to us via either submit@scirp.org or Online Submission Portal.
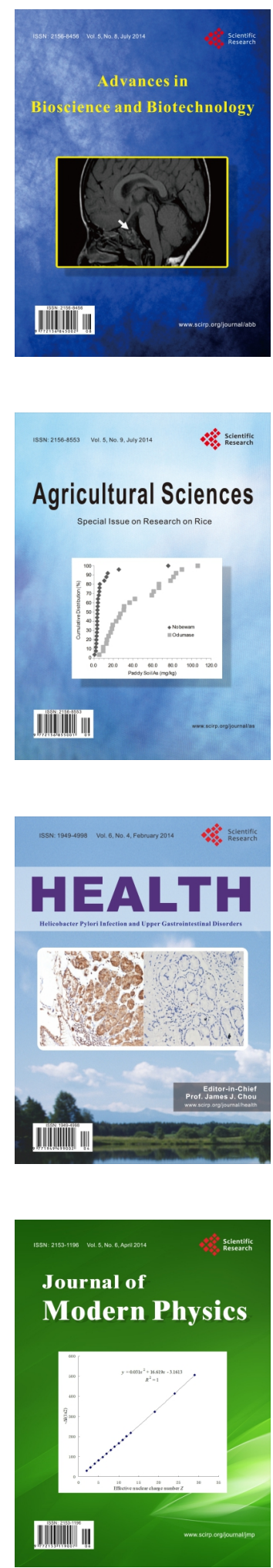
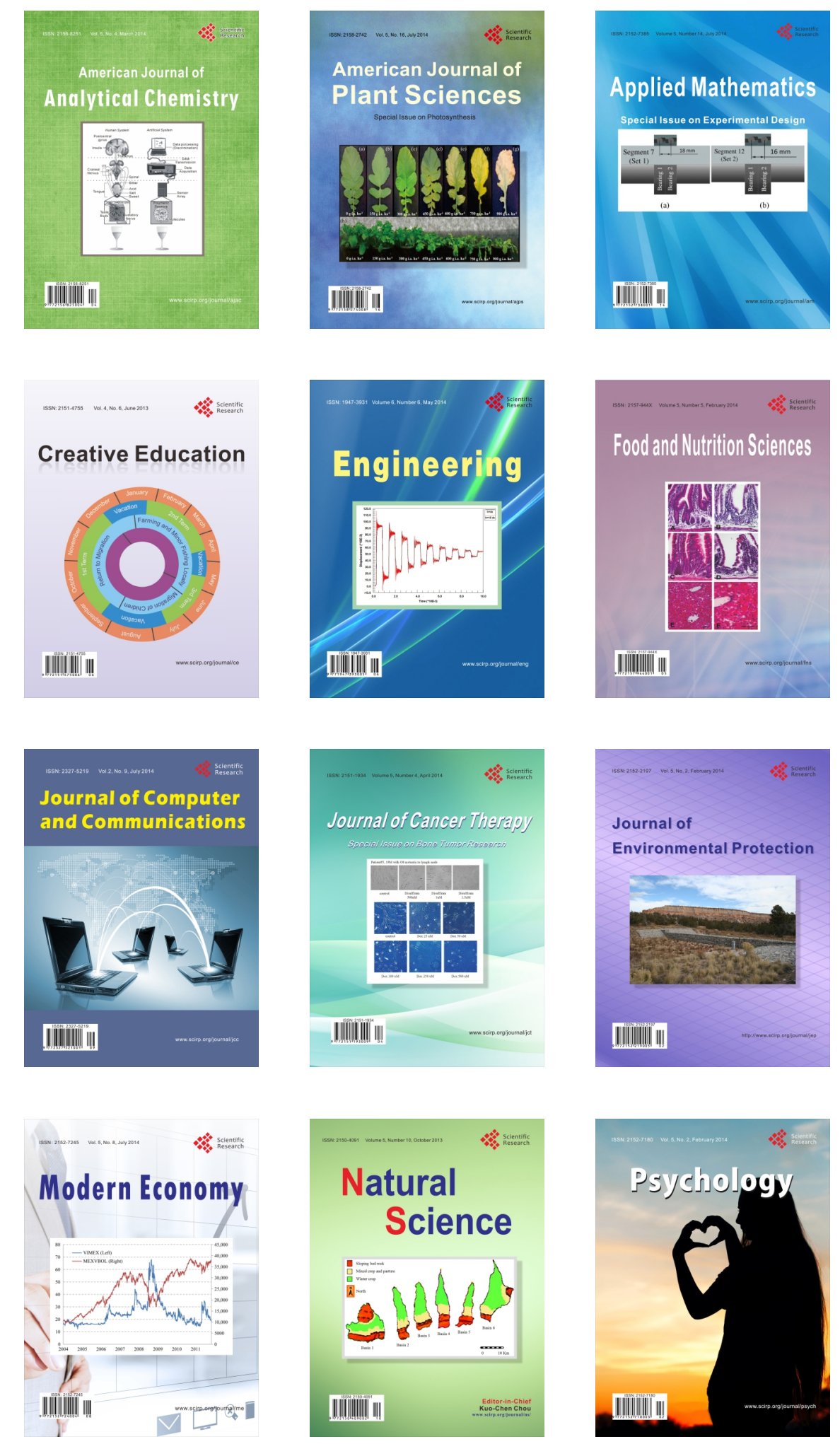